\title{
RESEARCH
}

\section{Lymph node characteristics of 6279 N1 differentiated thyroid cancer patients}

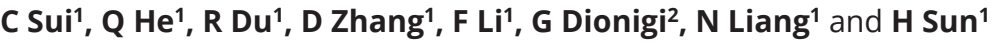 \\ 'Division of Thyroid Surgery, China-Japan Union Hospital of Jilin University, Jilin Provincial Key Laboratory of Surgical Translational Medicine, Jilin \\ Provincial Precision Medicine Laboratory of Molecular Biology and Translational Medicine on Differentiated Thyroid Carcinoma, Changchun City, China \\ 2Division for Endocrine and Minimally Invasive Surgery, Department of Human Pathology in Adulthood and Childhood 'G. Barresi', \\ University Hospital 'G. Martino', The University of Messina, Messina, Italy
}

Correspondence should be addressed to H Sun or N Liang: thyroidjl@163.com or liangnan2006@163.com

\begin{abstract}
Purpose: This study examined the clinicopathological characteristics of 6279 N1 differentiated thyroid cancer (DTC) patients who underwent operations in our center. Methods: This was a retrospective longitudinal analysis. We categorized the DTC patients on the basis of various lymph node (LN) characteristics. Logistic regression models and multiple linear regression models were used for the correlation analysis.

Results: A total of 3693 (58.8\%) N1a patients and 2586 (41.2\%) N1 b patients were included. Patients with $\mathrm{N} 1 \mathrm{~b}$ disease had larger metastatic foci $(0.5 \mathrm{vs} 0.15 \mathrm{~cm})$, a greater number of metastatic LNs (5 vs 2), a greater number of dissected LNs ( 25 vs 7 ), and a smaller lymph node ratio (NR, number of positive LNs/number of sampled LNs) (23.1\% vs $28.6 \%$ ) than patients in stage N1a. Comparing the clinicopathological features, we found that male, increased tumor size, multifocality, and thyroiditis increased the risk of stage $\mathrm{N} 1 \mathrm{~b}$ disease $(P<0.05)$. Sex, multifocality, capsular infiltration, and tumor size were associated with the size of the metastatic LNs $(P<0.05)$. Sex, capsular infiltration, and nodular goiter were associated with the NR $(P<0.05)$. Female sex, tumor located in inferior lobe, maximal tumor diameter (MTD) $<1 \mathrm{~cm}$, and nodular goiter were independent predictors for skip metastases $(P<0.05)$. MTD $>1 \mathrm{~cm}$, central neck metastasis and age were independent predictors for bilateral lateral neck metastasis (BLNM) $(P<0.05)$.

Conclusion: The LN characteristics of stage $\mathrm{N} 1 \mathrm{a}$ and $\mathrm{N} 1 \mathrm{~b}$ disease were associated with significantly different features, such as sex, tumor size, multifocality, capsular infiltration, and nodular goiter.
\end{abstract}

\section{Introduction}

According to the current 8th edition of the American Joint Committee on Cancer staging system, the $\mathrm{N}$ stage in TC is determined by the location of positive LNs, and other LNs features (i.e., the number of positive LNs, number of sampled LNs, size of the largest positive LN, size of the largest metastatic focus within a $\mathrm{LN}$, and lymph node ratio (NR)) were considered as potential prognostic factors (1). The size and number of positive LNs have been included in the risk stratification system in the American Thyroid Association (ATA) guidelines (2). In recent years, LN metastasis has attracted more and more attention $(3,4)$, which could significantly affect the prognosis of TC (Table 1). In patients with inappropriately dissected cervical nodes, however, a discrepancy may exist between the absolute number of positive nodes and the substantive extent of differentiated thyroid cancer (DTC) node metastasis $(1,2,6)$. Therefore, the NR, defined as the absolute number of positive nodes/number of
This work is licensed under a Creative Commons Attribution-NonCommercial-NoDerivatives 4.0 enternationad ticense.ifica.com at 04/25/2023 11:44:10PM 
Table 1 The diagnostic value of lymph nodes metastasis in thyroid cancer.

\begin{tabular}{|c|c|c|c|}
\hline References & LN values & Outcomes & $\begin{array}{c}\text { Predictive } \\
\text { validity }(+/-)\end{array}$ \\
\hline Randolph GW (5) & $\begin{array}{l}\text { Number of } \\
\text { positive LNs }\end{array}$ & $\begin{array}{l}\text { Risk } \\
\text { stratification }\end{array}$ & + \\
\hline Schneider DF (6) & NR & DSM & + \\
\hline Beal SH (7) & NR & Survival & - \\
\hline Wu MH (8) & $\begin{array}{l}\text { Number of } \\
\text { positive LNs }\end{array}$ & $\begin{array}{l}\text { Risk } \\
\text { stratification }\end{array}$ & + \\
\hline \multirow[t]{2}{*}{ Kim HI (9) } & $\begin{array}{l}\text { Number of } \\
\text { positive LNs }\end{array}$ & CSM & + \\
\hline & $\begin{array}{l}\text { Size of } \\
\text { positive LNs }\end{array}$ & CSM & + \\
\hline Ito $Y(10)$ & $\begin{array}{l}\text { Size of } \\
\text { positive LNs }\end{array}$ & Recurrence & + \\
\hline Adam M (11) & $\begin{array}{l}\text { Number of } \\
\text { positive LNs }\end{array}$ & OS & + \\
\hline Kim M (12) & $\begin{array}{l}\text { Size of } \\
\text { positive LNs }\end{array}$ & DSS & + \\
\hline Jeon MJ (13) & $\begin{array}{l}\text { Location of } \\
\text { positive LNs }\end{array}$ & DSM & + \\
\hline Vrachimis A (14) & $\begin{array}{l}\text { Location of } \\
\text { positive LNs }\end{array}$ & EFS & + \\
\hline
\end{tabular}

CSM, cancer-specific mortality; DSM, disease-specific mortality; DSS, disease-specific survival; EFS, event free survival; LNs, lymph nodes; Location of positive LNs, N1a and N1 b; NR, lymph node ratio; OS, overall survival.

excised nodes, has been suggested to address this discrepancy $(15,16)$. However, no consensus has been reached regarding the appropriate criteria to discriminate between low- and high-risk groups of NR values for TC $(15,16)$.

In the current study, we examined the clinicopathological characteristics of 6279 consecutive stage N1 DTC patients. To the best of our knowledge, the present study is the largest study to examine the characteristics of LNs in patients with DTC.

\section{Materials and methods}

\section{Study design}

A retrospective study was conducted in line with the STROCSS criteria (17).

\section{Setting}

The Thyroid Surgery Division in China-Japan Union Hospital of Jilin University is the largest referral and academic endocrine surgery center in the northeastern region of China. Surgical treatment was performed by dedicated surgeons who belonged to the same high-volume
TC surgical unit and who have extensive experience in endocrine surgery (i.e. 3500 thyroidectomies/year and 100,000 outpatients/year).

\section{Study population}

We retrospectively analyzed patients with stage N1 DTC. The time frame of 2008-2017 was selected. Patients older than 18 years, who had received surgical treatment, and a pathologically confirmed diagnosis of N1 DTC were included in the study. The exclusion criteria were as follows: patients for whom the number of examined or positive regional LNs was 0 or unknown (Nx), N0 patients, patients with occult cancer, patients who had the surgery outside our hospital, patients with recurrent TC cancer or a history of TC, patients with incomplete follow-up and non-primary TC, and patients with known secondary cancers. All patients qualified for surgical treatment underwent preoperative thyroid stimulating hormone (TSH), free thyroxine-4 (fT4), and free thyroxine-3 (fT3) tests and neck ultrasonography (2). Fine-needle aspiration biopsy (FNAB) and preoperative CT were not routinely employed. All patients after surgical treatment required L-tyrosine supplementation (2). The follow-up period was from the date of surgery to the date of the last clinical follow-up.

\section{Data source, collection and variables}

The institutional electronic database of the Thyroid Surgery Division in China-Japan Union Hospital of Jilin University was searched to identify N1 DTC patients who were treated between 2008 and 2017. Information on patients treated in the unit is prospectively collected for the continuous monitoring of quality indicators. The deidentified data include histology, information about the preoperative work-up, surgery details, multidisciplinary management, and follow-up. The local database was reviewed to identify patients who underwent surgery for primary N1 DTC. The data collection was carried out by completing a data sheet that included the clinicalhistopathological nature of the tumors and LN-related information.

\section{Definitions}

The ATA consensus statement regarding the terminology and classification of the central neck defines the central compartment LNs as all perithyroidal and paratracheal soft tissue and LNs with borders extending superiorly 
to the hyoid bone, inferiorly to the innominate artery, and laterally to the common carotid arteries. Whereas, the lateral neck includes submandibular and submental LNs (level I), the high (level IIA), mid- (level III), and lower jugular (level IV), and the supraclavicular (level V) and the upper deep jugular and spinal accessory LNs (level IIB) $(1,2,18)$.

\section{Surgery}

Patients in this study underwent open or endoscopic surgeries. The primary lesion was excised at the same time that the cervical LNs were dissected. Ipsilateral lobe and isthmus resection was performed for unilateral primary lesions. Total thyroidectomy was performed for unilateral primary lesions requiring iodine 131 treatment. We generally performed the LN dissection (LND) of ipsilateral cervical central VI, which is recommended in China $(19,20)$. For all bilateral primary lesions, total thyroidectomy and bilateral cervical central VI LND were performed. Additional lateral compartment neck dissections, including levels II, III, and IV, were performed if metastases were present in the lateral compartment, and no level I or V LND was performed unless lymph node metastasis to level I or $\mathrm{V}$.

\section{Pathological evaluation}

For all patients with TC, formalin-fixed, paraffinembedded tissue was centralized (China-Japan Union Hospital of Jilin University). All clinical specimens were examined by pathologists, whose observations were recorded. TC diagnosis was based on histopathology reports from surgical specimens. The tumor and LN were completely dissected. All the tumors and LNs were serially sectioned into slices that were $1 \mathrm{~mm}$ thick and submitted for histologic examination. Figure 1 shows the positive LNs in histological and gross specimens.

\section{Postoperative staging system}

The tumors were staged according to the tumor-nodemetastasis (TNM) classification system (1). Staging was performed based on the data collected using the American Joint Committee on Cancer (AJCC) guidelines (1).

\section{Outcomes analysis}

We retrieved baseline and clinical characteristics, including age at diagnosis, sex, maximum tumor diameter (MTD),

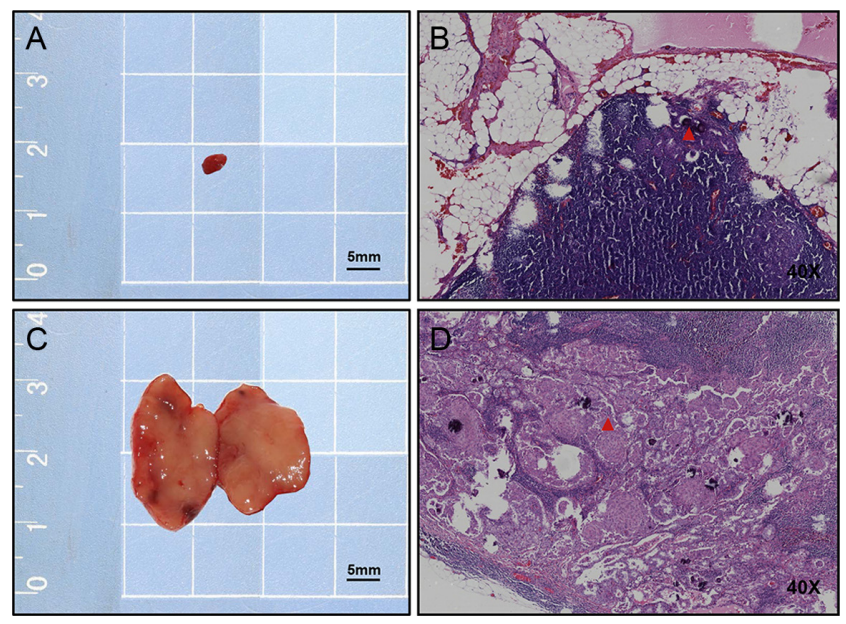

\section{Figure 1}

Positive lymph nodes (LNs) in histological and gross specimens. (A) microscopic foci of metastatic LN in gross specimens; (B) microscopic foci of metastatic LN in histological specimens (40x), maximum diameter of the metastatic tumor foci was $0.05 \mathrm{~cm}$; (C) macroscopic foci in gross specimens, maximum diameter of the metastatic tumor foci was $2.0 \mathrm{~cm}$; (D) macroscopic foci in histological specimens (40×). Red arrowheads: metastatic tumor foci.

multifocality, capsular invasion, thyroiditis, and nodular goiter. We categorized patients based on various LN characteristics, including location, size (maximum diameter of the metastatic tumor foci within a LN), number of positive and sampled LNs, and NR. The location and number of metastatic LNs were obtained from operative and pathologic reports. The NR was calculated as the number of positive LNs divided by the number of sampled LNs. Finally, the features of skip metastasis (i.e. lateral LN metastases without involvement in central compartment nodes) and bilateral lateral neck metastasis (BLNM) were examined.

\section{Location and classification of LN status}

According to the location of the positive LNs, LNs were classified as N1a or N1b. N1a: cancer has spread to the LNs around the thyroid (called the central compartment; the pretracheal, paratracheal, prelaryngeal LNs, and upper mediastinal LNs) $(1,2,18)$. N1b: cancer has spread beyond the central compartment, including unilateral cervical (LNs on 1 side of the neck), bilateral cervical (LNs on both sides of the neck), contralateral cervical (the opposite side of the tumor), or mediastinal (the chest) LNs $(1,2,18)$.

\section{Bias}

The selection bias was reduced by including all the N1 DTC patients. 


\section{Ethical approval}

All procedures performed in studies involving human participants were in accordance with the ethical standards of the institutional and/or national research committee and with the 1964 Helsinki declaration and its later amendments or comparable ethical standards. Approval of the Research Ethics Committee of China-Japan Union Hospital of Jilin University was obtained.

\section{Informed consent}

Informed consent was obtained from all individual participants included in the study.

\section{Statistical analysis}

We summarized continuous variables by arithmetic means and S.D. or medians and categorical values by weighted frequencies and percentages (\%). Data were analyzed using Student's $t$-test, the Mann-Whitney $U$ test, and the Kruskal-Wallis $H$ test for continuous variables and the chi-square test for categorical variables. A binary logistic regression model and a multiple linear regression model were used for the correlation analysis. A $P$ value of $<0.05$ was considered statistically significant. Statistical analyses were performed using IBM SPSS version 19.0.

\section{Results}

\section{Population}

In the period between June 2008 and December 2017, 15,005 patients with TC underwent primary surgery at our center (thyroid surgery in China-Japan Union Hospital of Jilin University). A total of 8621 patients (57.4\%) without neck metastasis and five patients $(0.03 \%)$ with incomplete information were excluded. A total of $6279 \mathrm{~N} 1$ consecutive patients were included in the final analysis (Fig. 2).

\section{Clinicopathological characteristics of patients}

All DTCs were confirmed to be N1 by the postoperative pathologic examination of resected tumor and LN tissues. A total of $3693(58.8 \%)$ patients had N1a disease and 2586 (41.2\%) had N1b disease. We further found that 1956 patients $(31.1 \%)$ had both central and lateral LN metastases. Only five $(0.8 \%)$ patients had contralateral N1b metastasis. The median number of positive LNs per procedure was 2 (1-44). The median maximum diameter (MD) of the metastatic foci within the LNs was $0.2 \mathrm{~cm}$ $(0.005-8 \mathrm{~cm})$.

\section{Time trend analysis of lymph node} pathological evaluation

In the 10-year period, the total numbers of positive and sampled LNs were 26,784 and 108,885 , respectively. The number of sampled LN increased from 6.5 (2008) to 21 (2010) and remained stable from 2010 to 2013 but decreased from 20 in 2013 to 7 in 2017. The NR decreased from $28 \%$ in 2008 to $12 \%$ in 2011, while it increased from 14\% in 2012 to 33\% in 2017 (Supplementary Table 1, see section on supplementary materials given at the end of this article).

\section{Features of lymph node metastasis based on the LN location}

Patients with N1b disease had larger metastatic foci (0.5 vs $0.15 \mathrm{~cm}, P<0.001)$, a greater number of metastatic

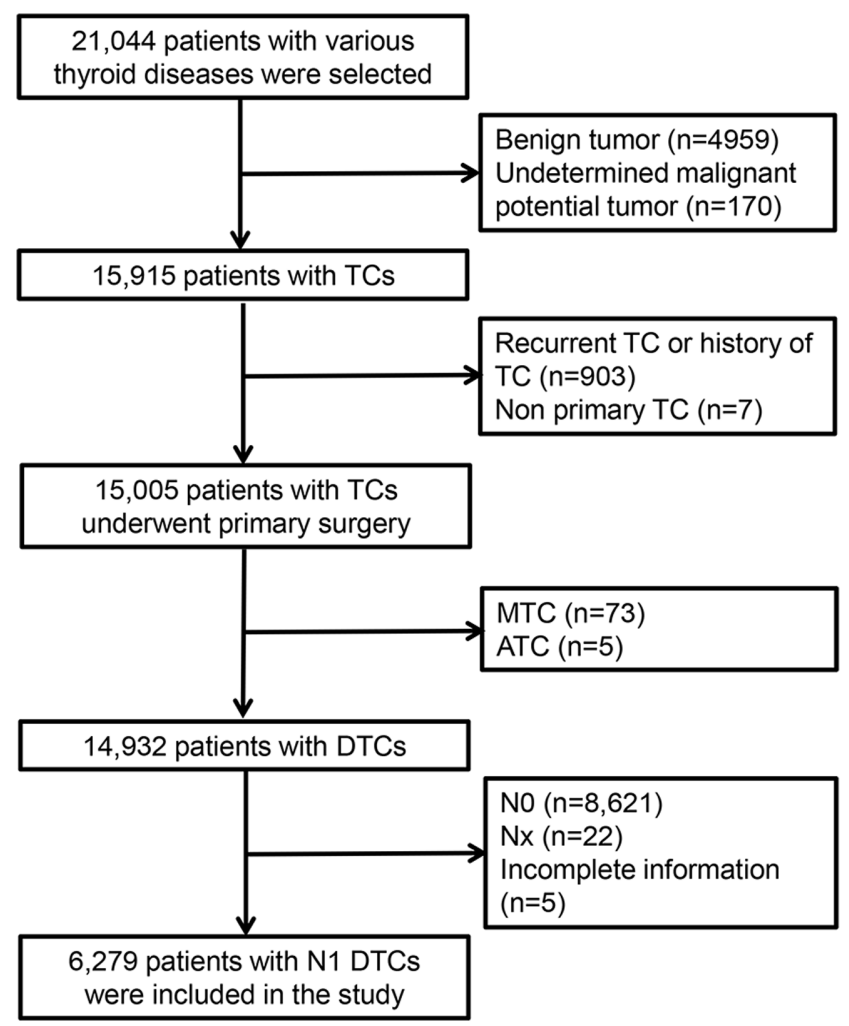

Figure 2

Flowchart for the inclusion and exclusion criteria. TC, thyroid cancer; MTC, medullary thyroid cancer; ATC, anaplastic thyroid cancer; DTC, differentiated thyroid cancer.

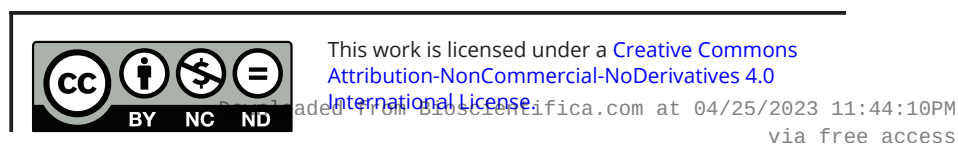


LNs (5 vs 2), a greater number of dissected LNs (25 vs $7, P<0.001)$, and a smaller NR $(23.1 \%$ vs $28.6 \%$, $P<0.001$ ) (Table 2).

Comparing the clinicopathological features of patients with N1a and N1b disease, we found that men had a 1.249 times higher risk of stage N1b disease than women. For every $1 \mathrm{~cm}$ increase in $\mathrm{T}$ size, the risk of stage N1b disease increased by $3.1 \%$. Multifocality $(\mathrm{OR}=1.443$, 95\%CI: 1.289-1.615) and thyroiditis $(\mathrm{OR}=1.197$, 95\%CI: 1.034-1.410) increased the risk of stage N1b disease. Capsular infiltration $(\mathrm{OR}=0.820$, 95\%CI: 0.713-0.944) and nodular goiter $(\mathrm{OR}=0.839$, 95\%CI: 0.732-0.962) decreased the risk of stage N1b disease (Table 3).

\section{Logistic regression model}

As shown in Table 4, male sex, multifocality, capsular infiltration, and tumor size were positively associated with the size of positive LNs, whereas advanced age and nodular goiter were negatively associated with the size of positive LNs $(P<0.05)$ in the multivariate logistic regression (except for thyroiditis). Male sex, capsular infiltration, and nodular goiter were associated with a higher NR, while advanced age, multifocality, and thyroiditis were associated with a lower NR $(P<0.05)$ (Table 5).

Our previous studies have found that trends of the central neck dissection (CND) and CND+lateral neck dissection (LND) changed dramatically between 2008 and 2017, as a result of the revision of the guidelines. And we noted that more extensive prophylactic LND of treating TCs was gradually giving way to therapeutic LND. The percentage of prophylactic LND increased from 13.9\% $(n=6)$ in 2008 to $31.0 \%(n=228)$ in 2013 and decreased to 1.3\% $(n=16)$ in 2017. Meanwhile, we also found that the NR was related to three different LNDs (including central LND, prophylactic LLND, and therapeutic LLND). After further statistical verification, the following formula was obtained: the median

Table 2 The lymph node characteristics of the location of lymph node metastasis (N1a vs N1b).

\begin{tabular}{llccccc}
\hline & & N1a & & N1b & & P value \\
\cline { 1 - 1 } \cline { 5 - 6 } Size of LNs involved (median) & & 0.15 & & 0.5 & & $<0.001$ \\
Number of LNs involved (median) & & & 5 & & $<0.001$ \\
Number of LNs sampled (median) & 7 & & 25 & & $<0.001$ \\
NR (median, \%) & & 28.6 & & 23.1 & & $<0.001$
\end{tabular}

NR, lymph node ratio, number of positive lymph nodes (LNs)/number of sampled LNs; Size of positive LNs, maximum diameter (MD) of the metastatic tumor foci within a LN.
Table 3 The related factors of the location of lymph node metastasis (N1a vs N1b)

\begin{tabular}{|c|c|c|}
\hline & OR $(95 \% \mathrm{Cl})$ & $P$ value \\
\hline \multicolumn{3}{|l|}{ Sex } \\
\hline Female & 1 & \\
\hline Male & $1.249(1.106-1.420)$ & $<0.001$ \\
\hline Tumor size & $3.126(2.859-3.418)$ & $<0.001$ \\
\hline \multicolumn{3}{|l|}{ Multifocality } \\
\hline No & 1 & \\
\hline Yes & $1.443(1.289-1.615)$ & $<0.001$ \\
\hline \multicolumn{3}{|c|}{ Capsular infiltration } \\
\hline No & 1 & \\
\hline Yes & $0.820(0.713-0.944)$ & 0.006 \\
\hline \multicolumn{3}{|l|}{ Thyroiditis } \\
\hline No & 1 & \\
\hline Yes & $1.197(1.034-1.410)$ & 0.016 \\
\hline \multicolumn{3}{|l|}{ Nodular goiter } \\
\hline No & 1 & \\
\hline Yes & $0.839(0.732-0.962)$ & 0.012 \\
\hline
\end{tabular}

aTumor size, maximum meridian of tumor.

$\mathrm{NR}$ is approximately equal to the weighted sum of the NRs of three LNDs: $\mathrm{r}_{\mathrm{M}} \approx \mathrm{r}_{\text {sum }}=\sum(\mathrm{rf} / n)=\mathrm{r}_{1} \mathrm{f}_{1} / n+\mathrm{r}_{2} \mathrm{f}_{2} / n+\mathrm{r}_{3} \mathrm{f}_{3} / n$ (Table 6). These LN features were affected by several factors, such as sex, age, tumor size, multifocality, capsular infiltration, and nodular goiter.

\section{N1b skip metastasis}

Females had a higher rate of skip metastases than males (26.2\%, vs $20.2 \%, P=0.001)$. Most patients were in the middle-aged or elderly groups $(35.7 \%$ and $34.6 \%$, $P<0.001)$. MTD $<1 \mathrm{~cm}$ and nodular goiter were associated more with skip metastasis (350 (55.6\%) and 487 (77.4\%), respectively) $(P<0.001)$. Capsular infiltration $(P=0.001)$ were rare in this subgroup analysis. Multifocality $(P=0.078)$ and thyroiditis $(P=0.619)$ were not found to be different between two groups. In multivariate analysis, female sex, advanced age, inferior lobe of the thyroid, MTD $<1 \mathrm{~cm}$, and nodular goiter were positively associated with the incidence of skip metastases $(P<0.05)$, whereas capsular infiltration $(P<0.05)$ was negatively associated with skip metastases. (Table 7).

\section{BLNM}

Of the 1548 patients with DTC located in one lobe, 1509 patients had unilateral lateral neck metastasis (ULNM) and 39 had BLNM. Younger age had a higher rate of BLNM (31 vs 39, $P<0.001)$. MTD > $1 \mathrm{~cm}$, multifocality, and thyroiditis were associated more with BLNM (31 (79.5\%), 15 (38.5\%), and 14 (35.9\%), respectively) $(P<0.05)$. 
Table 4 The related factors of the size of positive lymph nodes. ${ }^{a}$

\begin{tabular}{l}
\hline Variates \\
\hline Constant \\
Sex \\
Age \\
Multifocality \\
Capsular infiltration \\
Tumor size \\
Thyroiditis \\
Nodular goiter \\
\hline
\end{tabular}

\begin{tabular}{c}
\hline Unstandardized coefficients \\
\hline 0.232 \\
0.082 \\
-0.005 \\
0.09 \\
0.117 \\
0.197 \\
0.032 \\
-0.047
\end{tabular}

\begin{tabular}{l}
\hline S.E. \\
\hline 0.04 \\
0.015 \\
0.001 \\
0.014 \\
0.017 \\
0.009 \\
0.018 \\
0.017 \\
\hline
\end{tabular}

\begin{tabular}{c}
\hline Standardized coefficients \\
\hline 0.069 \\
-0.087 \\
0.082 \\
0.085 \\
0.27 \\
0.023 \\
-0.038 \\
\hline
\end{tabular}

\begin{tabular}{c}
\hline P value \\
\hline$<0.001$ \\
$<0.001$ \\
$<0.001$ \\
$<0.001$ \\
$<0.001$ \\
$<0.001$ \\
0.075 \\
0.005 \\
\hline
\end{tabular}

aWe evaluated the size of positive lymph nodes (LNs) using the maximum diameter (MD) of the metastatic tumor foci within a LN; ${ }^{\mathrm{b} T u m o r}$ size, maximum meridian of tumor.

Central neck metastasis $(P=0.003)$ was predominated in patients with BLNM. Sex, tumor location, capsular infiltration, and nodular goiter $(P>0.05)$ were not found to be different between the two groups. In addition, MTD $>1 \mathrm{~cm}$ and central neck metastasis were positively associated with BLNM $(P<0.05)$, whereas advanced age was negatively associated with BLNM $(P<0.05)$ in the multivariate logistic regression (Table 8).

\section{Discussion}

TC is a tumor with indolent behavior but with an early tendency to locoregional lymphatic spread $(21,22)$. The presence of $L N$ metastases in the setting of TC is a poor prognostic factor, and the importance of LN characterization is clear $(21,22)$. Furthermore, LN dissection is a surrogate for adequate staging, and it can be expected that the lower the lymph nodes harvested, the higher the probability that metastatic nodal disease will remain. The present study is the largest study to examine the characteristics of positive LNs in patients with DTC. The profiles of positive LN distribution and histological findings in the neck are depicted. LNs were stratified into $\mathrm{N} 1 \mathrm{a}$ or $\mathrm{N} 1 \mathrm{~b}$ according to the current 8th edition of the AJCC staging system (1).

\section{N1a vs N1b}

Our results showed that the LN characteristics of $\mathrm{N} 1 \mathrm{a}$ and N1b were associated with significantly different features.

An interesting finding for the N1b subgroup was the larger number of dissected LNs and small NR. Many patients with LN sampled from N1a would have DTC with a very small primary tumor size.

After the integral analysis of N1a DTC, we studied the characteristics of N1b DTC. Our analysis showed that $\mathrm{N} 1 \mathrm{~b}$ was significantly associated with larger metastatic foci, a greater number of positive LNs, and a decreased NR (Table 3). Male sex, tumor size, multifocality, capsular infiltration, and nodular goiter were independent risk factors with significant odds ratios (Tables 4, 5 and 6).

As reported previously for DTCs, the spread of the tumor into the surrounding normal tissue and vascular invasion were the most significant features predictive of nodal involvement $(15,23)$. In contrast, peritumoral thyroiditis correlated with a lack of nodal metastases, possibly reflecting an immunological reaction against the cancer and a suppressive function against the development of regional LN metastases $(15,23)$.

Table 5 The related factors of the NR. ${ }^{a}$

\begin{tabular}{lcc}
\hline Variates & & Unstandardized coefficients \\
\cline { 1 - 1 } Constant & 0.49 \\
Sex & 0.061 \\
Age & -0.003 \\
Multifocality & -0.033 \\
Capsular infiltration & 0.02 \\
Tumor size & -0.004 \\
Thyroiditis & -0.077 \\
Nodular goiter & 0.024 \\
\hline
\end{tabular}

\begin{tabular}{l}
\hline \multicolumn{1}{c}{ S.E. } \\
\hline 0.019 \\
0.007 \\
0 \\
0.006 \\
0.008 \\
0.004 \\
0.008 \\
0.008 \\
\hline
\end{tabular}

\begin{tabular}{c}
\hline Standardized coefficients \\
\hline \\
0.108 \\
-0.134 \\
-0.064 \\
0.031 \\
-0.012 \\
-0.121 \\
0.04 \\
\hline
\end{tabular}

$\begin{array}{r}\hline \text { P value } \\ \hline<0.001 \\ <0.001 \\ <0.001 \\ <0.001 \\ 0.015 \\ 0.339 \\ <0.001 \\ 0.003 \\ \hline\end{array}$

${ }^{a} \mathrm{NR}$, lymph node ratio, number of positive lymph nodes (LNs)/number of sampled LNs; ${ }^{\mathrm{b}}$ Tumor size, maximum meridian of tumor.

https://ec.bioscientifica.com https://doi.org/10.1530/EC-20-0019 (c) 2020 The authors Published by Bioscientifica Ltd

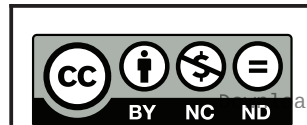

This work is licensed under a Creative Commons Attribution-NonCommercial-NoDerivatives 4.0 Internationab bicense ifica.com at 04/25/2023 11:44:10PM 
Table 6 The weighted calculation of lymph node ratio (NR).

\begin{tabular}{|c|c|c|}
\hline Years & $\begin{array}{c}\text { Number of } \\
\text { patients with LNM } \\
(n)\end{array}$ & $\mathbf{N R}\left(r_{M}\right)$ \\
\hline 2008 & 43 & 28.6 \\
\hline 2009 & 196 & 28.6 \\
\hline 2010 & 294 & 18.2 \\
\hline 2011 & 313 & 12.0 \\
\hline 2012 & 399 & 14.0 \\
\hline 2013 & 735 & 17.9 \\
\hline 2014 & 961 & 24.1 \\
\hline 2015 & 1032 & 25.7 \\
\hline 2016 & 1089 & 33.3 \\
\hline 2017 & 1217 & 33.3 \\
\hline
\end{tabular}

\begin{tabular}{|c|c|c|}
\hline \multicolumn{3}{|c|}{ CLND } \\
\hline$r_{1}$ & $f_{1}$ & $\mathrm{r}_{1} \mathrm{f}_{1} / n$ \\
\hline 21.4 & 7 & 3.5 \\
\hline 50.0 & 75 & 19.1 \\
\hline 18.2 & 47 & 2.9 \\
\hline 11.8 & 16 & 0.6 \\
\hline 14.3 & 13 & 0.5 \\
\hline 16.7 & 111 & 2.5 \\
\hline 33.3 & 399 & 13.8 \\
\hline 25.5 & 531 & 13.1 \\
\hline 33.3 & 760 & 23.3 \\
\hline 33.3 & 911 & 24.9 \\
\hline
\end{tabular}

\begin{tabular}{|c|c|c|}
\hline \multicolumn{3}{|c|}{ Prophylactic LLND } \\
\hline$r_{2}$ & $\mathrm{f}_{2}$ & $\mathrm{r}_{2} \mathrm{f}_{2} / n$ \\
\hline 17.7 & 6 & 2.5 \\
\hline 11.5 & 21 & 1.2 \\
\hline 9.1 & 70 & 2.2 \\
\hline 7.7 & 88 & 2.2 \\
\hline 7.7 & 113 & 2.2 \\
\hline 8.3 & 228 & 2.6 \\
\hline 8.3 & 165 & 1.4 \\
\hline 8.3 & 89 & 0.7 \\
\hline 8.7 & 27 & 0.2 \\
\hline 17.9 & 16 & 0.2 \\
\hline
\end{tabular}

\begin{tabular}{|c|c|c|c|}
\hline \multicolumn{3}{|c|}{ Therapeutic LLND } & \multirow[b]{2}{*}{$\mathbf{r}_{\text {sum }}$} \\
\hline$r_{3}$ & $f_{3}$ & $\mathrm{r}_{3} \mathrm{f}_{3} / n$ & \\
\hline 36.7 & 30 & 25.6 & 31.6 \\
\hline 24.0 & 100 & 12.3 & 32.6 \\
\hline 21.4 & 177 & 12.9 & 18.0 \\
\hline 13.6 & 209 & 9.1 & 11.9 \\
\hline 20.0 & 273 & 13.7 & 16.3 \\
\hline 20.0 & 396 & 10.8 & 15.9 \\
\hline 22.7 & 397 & 9.4 & 24.6 \\
\hline 24.1 & 412 & 9.6 & 23.5 \\
\hline 28.6 & 302 & 7.9 & 31.4 \\
\hline 29.8 & 291 & 7.1 & 32.3 \\
\hline
\end{tabular}

$f$, the number of patients underwent three lymph node dissections (LNDs), separately; $n$, number of patients with neck metastasis per year; $r_{M}$, the median NR of patients with neck metastasis per year; $r_{1}$, the median NR of patients underwent central LND (CLND) with neck metastasis per year; $r_{2}$, the median NR of patients underwent prophylactic lateral LND (LLND) with neck metastasis per year; $r_{3}$, the median NR of patients underwent therapeutic LLND with neck metastasis per year; $r_{\text {sum }}=\sum(r f / n)=r_{1} f_{1} / n+r_{2} f_{2} / n+r_{3} f_{3} / n$.

Table 7 Comparison of clinicopathologic characteristics between two groups (patients with skip metastasis or not).

\begin{tabular}{|c|c|c|c|c|c|}
\hline & \multicolumn{2}{|c|}{ Skip metastasis } & \multirow[b]{2}{*}{$P$ value } & \multirow[b]{2}{*}{ OR $(\mathrm{Cl})$} & \multirow[b]{2}{*}{$P$ value } \\
\hline & Present & Absent & & & \\
\hline Total & $629(24.3)$ & $1956(75.7)$ & & & \\
\hline \multicolumn{6}{|l|}{ Sex } \\
\hline Male & $163(20.2)$ & $642(79.8)$ & 0.001 & Ref. & NA \\
\hline Female & $466(26.2)$ & $1314(73.8)$ & & 2.195 (1.617-2.979) & $<0.001$ \\
\hline \multicolumn{6}{|l|}{ Age groups } \\
\hline Median & 43 & 38 & & $1.069(1.066-1.072)$ & $<0.001$ \\
\hline Children (<18 years) & $2(7.7)$ & $24(92.3)$ & $<0.001$ & Ref. & NA \\
\hline Youth (19-44 years) & $340(19.4)$ & $1412(80.6)$ & & $5.648(3.851-8.284)$ & $<0.001$ \\
\hline Middle age (45-59 years) & $260(35.7)$ & 469 (64.3) & & $3.000(2.704-3.328)$ & $<0.001$ \\
\hline Elderly (60+ years) & 27 (34.6) & $51(65.4)$ & & $2.426(2.248-2.618)$ & $<0.001$ \\
\hline \multicolumn{6}{|l|}{ Tumor lobe } \\
\hline Left lobe & $195(27)$ & $527(73)$ & 0.117 & NA & NA \\
\hline Right lobe & $204(24.7)$ & $622(75.3)$ & & NA & NA \\
\hline Isthmus & $2(33.3)$ & $4(66.7)$ & & NA & NA \\
\hline Bilaterlity & $228(22.1)$ & 803 (77.9) & & NA & NA \\
\hline \multicolumn{6}{|l|}{ Tumor location } \\
\hline Inferior lobe & $228(29.8)$ & $536(70.2)$ & $<0.001$ & Ref. & NA \\
\hline Middle lobe & $262(19.6)$ & $1076(80.4)$ & & $0.839(0.758-0.923)$ & $<0.001$ \\
\hline Superior lobe & $79(19.1)$ & 334 (80.9) & & $0.956(0.916-0.998)$ & 0.042 \\
\hline \multicolumn{6}{|l|}{ Tumor size } \\
\hline MTD < $1 \mathrm{~cm}$ & $350(55.6)$ & 774 (39.6) & $<0.001$ & Ref. & NA \\
\hline MTD > $1 \mathrm{~cm}$ & $279(44.4)$ & $1182(60.4)$ & & $0.620(0.602-0.639)$ & $<0.001$ \\
\hline \multicolumn{6}{|l|}{ Multifocality } \\
\hline Yes & $311(49.4)$ & $1046(53.5)$ & 0.078 & NA & NA \\
\hline No & $318(50.6)$ & 910 (46.5) & & NA & NA \\
\hline \multicolumn{6}{|l|}{ Capsular infiltration } \\
\hline Yes & $119(18.9)$ & 492 (25.2) & 0.001 & $0.750(0.723-0.778)$ & $<0.001$ \\
\hline No & $510(81.1)$ & $1464(74.8)$ & & Ref. & NA \\
\hline \multicolumn{6}{|l|}{ Thyroiditis present } \\
\hline Yes & $133(21.1)$ & $432(22.1)$ & 0.619 & NA & NA \\
\hline No & 496 (78.9) & 1524 (77.9) & & NA & NA \\
\hline \multicolumn{6}{|l|}{ Nodular goiter present } \\
\hline Yes & $487(77.4)$ & $1373(70.2)$ & $<0.001$ & $1.398(1.351-1.447)$ & $<0.001$ \\
\hline No & $142(22.6)$ & $583(29.8)$ & & Ref. & NA \\
\hline
\end{tabular}

Skip metastasis, lateral LN metastases without involvement in central compartment nodes; MTD, maximum tumor diameter.

https://ec.bioscientifica.com https://doi.org/10.1530/EC-20-0019
(C) 2020 The authors Published by Bioscientifica Ltd

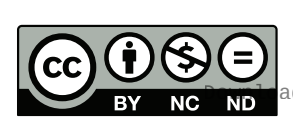

This work is licensed under a Creative Commons Attribution-NonCommercial-NoDerivatives 4.0 Internationab ticense.ifica com at 04/25/2023 11:44:10PM 
Table 8 Comparison of clinicopathologic characteristics between patients with unilateral and bilateral lateral neck metastases.

\begin{tabular}{l}
\hline \\
\hline Total \\
Sex \\
Male \\
Female \\
Age \\
Median \\
$<45$ years \\
$>45$ years \\
Tumor lobe \\
Left lobe \\
Right lobe \\
Tumor location \\
Inferior lobe \\
Middle lobe \\
Superior lobe \\
Tumor size \\
MTD 1 cm \\
MTD 1 cm \\
Multifocality \\
Yes \\
No \\
Capsular infiltration \\
Yes \\
No \\
Thyroiditis present \\
Yes \\
No \\
Nodular goiter present \\
Yes \\
No \\
Central neck metastasis \\
Yes \\
No \\
\\
\end{tabular}

\begin{tabular}{c}
\hline BLNM \\
\hline $39(2.5)$ \\
$15(38.5)$ \\
$24(61.5)$
\end{tabular}

$\frac{\text { ULNM }}{1509(97.5)}$

$479(31.7)$
$1030(68.3)$

31
$33(84$
$6(15)$

$6(15.4)$

$18(46.2)$

$21(53.8)$

8 (20.5)

27 (69.2)

4 (10.3)

8 (20.5)

31 (79.5)

15 (38.5)

24 (61.5)

12 (30.8)

$27(69.2)$

14 (35.9)

$25(64.1)$

30 (76.9)

9 (23.1)

37 (94.9)

2 (5.1)

39

1063 (70.4)

446 (29.6)

704 (46.7)

805 (53.3)

522 (34.6)

760 (50.4)

227 (15)

$680(45.1)$

829 (54.9)

311 (20.6)

1198 (79.4)

316 (20.9)

$1193(79.1)$

1181 (78.3)

$1280(84.8)$

229 (15.2)

1112 (73.7)

$397(26.3)$

P value

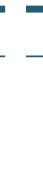

OR $(\mathrm{Cl})$

328 (21.7)
0.374

NA

NA

$<0.001$

0.055

0.951

0.066

NA

0.002

0.006

0.138

0.035

0.177

0.003

NA
NA
$0.959(0.925-0.994)$
NA
NA
NA
NA
NA
NA
NA
Ref.
$2.288(1.176-4.452)$
1.142 (0.876-1.490)
Ref.
NA
NA
5.204 (1.217-22.253)
Ref.
NA
Ref.
NA
NA

NA

NA

0.023

NA

NA

NA

NA

NA

NA

NA

NA

0.015

0.326

NA

NA

NA

0.063

NA

NA

NA

0.026

NA

BLNM, bilateral lateral neck metastasis; MTD, maximum tumor diameter; ULNM, unilateral lateral neck metastasis.

\section{Skip metastasis}

Subsequently, we noted that female sex, advanced age, inferior lobe of the thyroid, $\mathrm{MTD}<1 \mathrm{~cm}$, and nodular goiter were positively associated with the incidence of skip metastases, while capsular infiltration was negatively associated with skip metastases in multivariate analysis. Similar to these results, Jin et al. and Nie et al. also found that small TCs $(\mathrm{MTD}<1 \mathrm{~cm})$ are more likely to have skip metastases $(24,25)$.

\section{BLNM}

Finally, we found that MTD $>1 \mathrm{~cm}$, central neck metastasis, and age were significantly associated with BLNM in the multivariate analysis. Additionally, another study indicated that males, and patients with a primary tumour size $>2 \mathrm{~cm}$, aggressive subtype of PTC, central node metastasis, and Delphian node metastasis are more likely to have BLNM (4).

\section{Limits}

The limitations of the study should be acknowledged. In the present study, histopathological features, such as sex, tumor size, multifocality, capsular infiltration, nodular goiter and so on, differed significantly between N1a and $\mathrm{N} 1 \mathrm{~b}$ diseases, but this information was available only after surgery and was not useful for planning surgery. Second, because this analysis was conducted retrospectively with data from a single institution, the registration information, patient volume, and inspection items could not be designed beforehand. Third, lateral compartment LN dissection was not performed on a part of patients in the lateral compartment clinical LN-negative group. Subclinical lateral compartment LN metastases may exist. The follow-up and disease recurrence information were not included in the current report. Prospective and multicenter clinical trials should be performed to provide more supporting evidence with greater reliability. 


\section{Supplementary materials}

This is linked to the online version of the paper at https://doi.org/10.1530/ EC-20-0019.

\section{Declaration of interest}

The authors declare that there is no conflict of interest that could be perceived as prejudicing the impartiality of the research reported.

\section{Funding}

This work was supported by the National Nature Science Foundation of China (81702651, 81972499), the Jilin Province Science and Technology Development Program (20180520123JH, 20190201275JC), the Program from the education department of Jilin Province (JJKH20190075KJ), and the Program of Jilin provincial finance department (2018SCZ007).

\section{Acknowledgements}

The authors sincerely thank all the clinicians in the division for their support. They were Guang Zhang, Le Zhou, Xuehai Bian, Xiaoli Liu, Shijie Li, Lina Zhao, Jingting Li, Qingfeng Fu, Hongbo Li, Yishen Zhao, Gaofeng Xue, Xueyan Zhang, Tie Wang, Changlin Li, Jiao Zhang, Jingwei Xin and Tianyu Yu.

\section{References}

1 Amin MB, Greene FL, Edge SB, Compton CC, Gershenwald JE, Brookland RK, Meyer L, Gress DM, Byrd DR \& Winchester DP. AJCC cancer staging manual: continuing to build a bridge from a population-based to a more "personalized" approach to cancer staging. CA: A Cancer Journal for Clinicians 201767 93-99. (https:// doi.org/10.3322/caac.21388)

2 Haugen BR, Alexander EK, Bible KC, Doherty GM, Mandel SJ, Nikiforov YE, Pacini F, Randolph GW, Sawka AM, Schlumberger M, et al. 2015 American Thyroid Association management guidelines for adult patients with thyroid nodules and differentiated thyroid cancer: the American Thyroid Association Guidelines Task Force on Thyroid Nodules and Differentiated Thyroid Cancer. Thyroid 201626 1-133. (https://doi.org/10.1089/thy.2015.0020)

3 Albers MB, Nordenstrom E, Wohlfahrt J, Bergenfelz A \& Almquist M. Sentinel lymph node biopsy in thyroid cancer. World Journal of Surgery 202044 142-147. (https://doi.org/10.1007/s00268-01905218-1)

4 Kim SY, Kim SM, Chang H, Kim BW, Lee YS, Chang HS \& Park CS. Lateral neck metastases in the ipsilateral and contralateral compartments of papillary thyroid carcinoma located in one lobe. ANZ Journal of Surgery 201989 E498-E501. (https://doi.org/10.1111/ ans.15458)

5 Randolph GW, Duh QY, Heller KS, LiVolsi VA, Mandel SJ, Steward DL, Tufano RP, Tuttle RM \& American Thyroid Association Surgical Affairs Committee's Taskforce on Thyroid Cancer Nodal Surgery. The prognostic significance of nodal metastases from papillary thyroid carcinoma can be stratified based on the size and number of metastatic lymph nodes, as well as the presence of extranodal extension. Thyroid 201222 1144-1152. (https://doi. org/10.1089/thy.2012.0043)

6 Schneider DF, Chen H \& Sippel RS. Impact of lymph node ratio on survival in papillary thyroid cancer. Annals of Surgical Oncology 201320 1906-1911. (https://doi.org/10.1245/s10434012-2802-8)

7 Beal SH, Chen SL, Schneider PD \& Martinez SR. An evaluation of lymph node yield and lymph node ratio in well-differentiated thyroid carcinoma. American Surgeon 201076 28-32.
$8 \mathrm{Wu} \mathrm{MH}$, Shen WT, Gosnell J \& Duh QY. Prognostic significance of extranodal extension of regional lymph node metastasis in papillary thyroid cancer. Head and Neck 201537 1336-1343. (https://doi. org/10.1002/hed.23747)

9 Kim HI, Kim K, Park SY, Choe JH, Kim JH, Kim JS, Oh YL, Hahn SY, Shin JH, Ahn HS, et al. Refining the eighth edition AJCC TNM classification and prognostic groups for papillary thyroid cancer with lateral nodal metastasis. Oral Oncology 201878 80-86. (https://doi. org/10.1016/j.oraloncology.2018.01.021)

10 Ito Y, Kudo T, Kobayashi K, Miya A, Ichihara K \& Miyauchi A. Prognostic factors for recurrence of papillary thyroid carcinoma in the lymph nodes, lung, and bone: analysis of 5,768 patients with average 10-year follow-up. World Journal of Surgery 201236 1274-1278. (https://doi.org/10.1007/s00268012-1423-5)

11 Adam MA, Pura J, Goffredo P, Dinan MA, Reed SD, Scheri RP, Hyslop T, Roman SA \& Sosa JA. Presence and number of lymph node metastases are associated with compromised survival for patients younger than age 45 years with papillary thyroid cancer. Journal of Clinical Oncology 201533 2370-2375. (https://doi.org/10.1200/ JCO.2014.59.8391)

12 Kim M, Jeon MJ, Oh HS, Park S, Song DE, Sung TY, Kim TY, Chung KW, Kim WB, Shong YK, et al. Prognostic implication of N1b classification in the eighth edition of the tumor-node-metastasis staging system of differentiated thyroid cancer. Thyroid $2018 \mathbf{2 8}$ 496-503. (https://doi.org/10.1089/thy.2017.0473)

13 Jeon MJ, Kim WG, Kim TH, Kim HK, Kim BH, Yi HS, Kim ES, Kim H, Kim YN, Kim EH, et al. Disease-specific mortality of differentiated thyroid cancer patients in Korea: a multicenter cohort study. Endocrinology and Metabolism 201732 434-441. (https://doi.org/10.3803/EnM.2017.32.4.434)

14 Vrachimis A, Wenning C, Gerss J, Dralle H, Vaez Tabassi M, Schober O, Riemann B \& MSDS study group. Not all DTC patients with $\mathrm{N}$ positive disease deserve the attribution "high risk". contribution of the MSDS trial. Journal of Surgical Oncology 2015112 9-14. (https://doi.org/10.1002/jso.23948)

15 Vas Nunes JH, Clark JR, Gao K, Chua E, Campbell P, Niles N, Gargya A \& Elliott MS. Prognostic implications of lymph node yield and lymph node ratio in papillary thyroid carcinoma. Thyroid 2013 23 811-816. (https://doi.org/10.1089/thy.2012.0460)

16 Gleisner AL, Mogal H, Dodson R, Efron J, Gearhart S, Wick E, Lidor A, Herman JM \& Pawlik TM. Nodal status, number of lymph nodes examined, and lymph node ratio: what defines prognosis after resection of colon adenocarcinoma? Journal of the American College of Surgeons 2013217 1090-1100. (https://doi.org/10.1016/j. jamcollsurg.2013.07.404)

17 Agha RA, Borrelli MR, Vella-Baldacchino M, Thavayogan R, Orgill DP, Pagano D, Pai PS, Basu S, McCaul J, Millham F, et al. The STROCSS statement: strengthening the reporting of cohort studies in surgery. International Journal of Surgery 201746 198-202. (https://doi. org/10.1016/j.ijsu.2017.08.586)

18 Carty SE, Cooper DS, Doherty GM, Duh QY, Kloos RT, Mandel SJ, Randolph GW, Stack Jr BC, Steward DL, Terris DJ, et al. Consensus statement on the terminology and classification of central neck dissection for thyroid cancer. Thyroid 200919 1153-1158. (https:// doi.org/10.1089/thy.2009.0159)

19 Lan XB \& Zhang H. An introduction of surgical update in 2015 American Thyroid Association management guidelines for adult patients with thyroid nodules and differentiated thyroid cancer. Zhonghua Wai Ke Za Zhi 201654 172-176. (https://doi.org/10.3760/ cma.j.issn.0529-5815.2016.03.004)

20 Chinese Medical Association Endocrinology Branch. Management guidelines for patients with thyroid nodules and differentiated thyroid cancer. Chinese Journal of Clinical Oncology 2012 39 1249-1272. (https://doi.org/10.3969/j.issn.1000-8179.2012. 17.001)

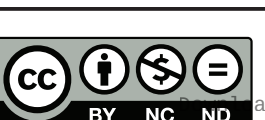

This work is licensed under a Creative Commons Attribution-NonCommercial-NoDerivatives 4.0 elnternationab bicense.ifica . com at 04/25/2023 11:44:10PM 
21 Kim YS \& Park WC. Clinical predictors of right upper paraesophageal lymph node metastasis from papillary thyroid carcinoma. World Journal of Surgical Oncology 201210 164. (https://doi. org/10.1186/1477-7819-10-164)

22 Podnos YD, Smith D, Wagman LD \& Ellenhorn JD. The implication of lymph node metastasis on survival in patients with welldifferentiated thyroid cancer. American Surgeon 200571 731-734.

23 Nishida T, Katayama Si \& Tsujimoto M. The clinicopathological significance of histologic vascular invasion in differentiated thyroid carcinoma. American Journal of Surgery 2002183 80-86. (https://doi. org/10.1016/s0002-9610(01)00843-1)

24 Jin WX, Jin YX, Ye DR, Zheng ZC, Sun YH, Zhou XF, Li Q, Wang OC, Liu HG \& Zhang XH. Predictive factors of skip metastasis in papillary thyroid cancer. Medical Science Monitor 201824 2744-2749. (https:// doi.org/10.12659/MSM.907357)

25 Nie X, Tan Z \& Ge M. Skip metastasis in papillary thyroid carcinoma is difficult to predict in clinical practice. BMC Cancer 201717702 (https://doi.org/10.1186/s12885-017-3698-2)

Received in final form 16 January 2020

Accepted 20 January 2020

Accepted Manuscript published online 21 January 2020 (c) 2020 The authors Published by Bioscientifica Ltd
This work is licensed under a Creative Commons Attribution-NonCommercial-NoDerivatives 4.0 Internationad ticense ifica.com at 04/25/2023 11:44:10PM 